\title{
The Prognostic Risk Factors of ECMO in Patients with Cardiogenic Shock: A Retrospective Cohort Analysis
}

\author{
Xiao-Zu Liao, MD,${ }^{1,2 *}$ Zhi-Bin Zhou, MD ${ }^{1 *}$ Zhou Cheng, MD, ${ }^{2}$ Xiao-Yu Yang, MD,${ }^{1}$ Xue Zhou, MD, ${ }^{1}$ \\ Bin-Fei Li, MD, ${ }^{2}$ Xia Feng, MD, $\mathrm{PhD}^{1}$
}

${ }^{1}$ Department of Anesthesiology, The First Affiliated Hospital of Sun Yat-Sen University, Guangzhou; ${ }^{2}$ Department of Anesthesiology, Zhongshan Affiliated Hospital of Sun Yat-Sen University, Zhongshan, China

\section{ABSTRACT}

Background: Advances in ECMO have rapidly progressed in recent years; however, the clinical mortality rate remains high. This study aimed to identify the risk factors of ECMO in patients with cardiogenic shock.

Methods: Data of patients with cardiogenic shock who received ECMO from January 2006 to August 2013 at the Affiliated Hospital of Sun Yat-Sen University were retrospectively analyzed. All patients with cardiogenic shock were divided into two groups according to whether death occurred in the hospital. The possible prognostic risk factors of ECMO were first obtained in a univariate analysis of the two groups, and the risk factors that affected the prognosis of patients who underwent ECMO were determined using a logistic regression analysis.

Results: This study included 94 cardiogenic shock patients who were treated with ECMO. Overall, 59 patients were successfully weaned from ECMO, which accounted for $62.7 \%$ of all patients. The multivariate analysis indicated that the independent risk factors associated with prognosis included ECMO timing $(\mathrm{OR}=7.68$; $95 \%$ CI 1.60-37.01), the occurrence of postoperative $\mathrm{MOF}(\mathrm{OR}=2,823.09$; $95 \% \mathrm{CI} 14.75$ $540,171.06)$, and the lactate level at weaning (OR = 493.17; 95\% CI: $1.55-156,653.27)$.

Conclusion: For patients with refractory cardiogenic shock, the early establishment of ECMO, improvement in perfusion, and the prevention of complications may improve the prognosis.

\section{INTRODUCTION}

During extracorporeal membrane oxygenation (ECMO), blood is drawn from a vein, oxygen is absorbed through a

Received February 23, 2017; revised received May 14, 2017; accepted fune 1, 2017.

*Both authors contributed equally to this work.

This work was supported by National Natural Science Foundation of China (81571032), Guangdong Science and Technology Planning Project (2013B051000045), Guangzhou International Science and Technology Cooperation Project (201275100019) and B.Braun Research Fund for Anesthesiology (No. BBDF-2014-016).

Correspondence: Xia Feng, MD, PhD, Department of Anesthesiology, The First Affiliated Hospital of Sun Yat-Sen University, No. 58 Zhongshan 2nd Road, Guangzhou 510080, China; (e-mail: fengxia@mail.sysu.edu.cn). membrane lung, and carbon dioxide is removed from the blood. After gas exchange, blood is driven by a pump and returned to the vein or returned to the artery. In 1972, Hill et al first reported the prolonged application of ECMO in a trauma patient with respiratory failure [Hill 1972]. Subsequently, hospitals have used this method to rescue patients with respiratory failure or heart failure. ECMO has been successfully used in patients with hypoxemia or decompensated hypercapnia caused by severe acute respiratory failure [Peek 2009; Davies 2009; Noah 2009; PAtroniti 2009] and in lung transplant recipients in the perioperative period [Cottini 2013]. As a method of heart support, ECMO is widely used in patients with low cardiac output after cardiac surgery [Ko 2002; Slottosch 2013; Bhat 2013], cardiogenic shock complicated by refractory acute myocardial infarction [Kim 2012; Tsao 2012 [, refractory cardiogenic shock in cardiomyopathy [Bermudez 2011], and refractory cardiogenic shock due to acute fulminant myocarditis [Yuan 2006; Fayssoil 2010]. In addition, ECMO is used during the perioperative period of heart transplantation [Ko 1997]. Advances in ECMO have rapidly progressed in recent years; however, the clinical mortality rate remains high. The survival rate of discharged patients undergoing auxiliary ECMO (supported on ECMO) was reported to range from 40\%-60\% [Langley 1998; Chaturvedi 2004; Delius 1992]. To improve the prognosis of patients, this study aimed to identify the risk factors of ECMO in patients with cardiogenic shock. The results of this study are expected to better guide clinical practice and to lay the foundation for the successful treatment of patients with appropriate prophylactic measures.

Table 1. Prognosis of Patients with Cardiogenic Shock Treated with Extracorporeal Membrane Oxygenation

\begin{tabular}{lccc}
\hline $\begin{array}{l}\text { Cause of Cardiogenic } \\
\text { Shock, } \mathrm{n}(\%)\end{array}$ & Total & $\begin{array}{c}\text { Cases of Successful } \\
\text { Weaning }\end{array}$ & $\begin{array}{c}\text { Cases of Survival } \\
\text { at Discharge }\end{array}$ \\
\hline $\begin{array}{l}\text { Low cardiac output after } \\
\text { cardiac surgery }\end{array}$ & 43 & $32(74.4)$ & $23(53.35)$ \\
$\begin{array}{l}\text { Fulminant myocarditis } \\
\text { Acute myocardial infarction }\end{array}$ & 21 & $16(76.2)$ & $16(76.2)$ \\
Cardiomyopathy & 9 & $7(38.9)$ & $6(33.3)$ \\
Pulmonary embolism & 3 & $2(22.2)$ & $1(11.1)$ \\
& $2(66.7)$ & $1(33.3)$
\end{tabular}




\section{METHODS}

\section{Inclusion Criteria}

The inclusion criteria for the patients in this study were as follows: patients 18 years of age or older who were undergoing ECMO due to cardiogenic shock from January 2006 to August 2013 at the Affiliated Hospital of Sun Yat-Sen University. Cardiogenic shock may have been caused by low cardiac output after heart surgery, complicated acute myocardial infarction, acute fulminant myocarditis, cardiomyopathy, and severe pulmonary embolism. Patients continued to experience cardiogenic shock after receiving traditional treatment, such as drugs and an auxiliary intraaortic balloon pump [IABP]. Our analysis looked retrospectively at outcomes for a large cohort of patients treated. All data analyzed were collected as part of routine diagnosis and treatment. The paper does not report on the use of experimental or new protocols. The Institutional Review Board was approached and waived the need for ethical approval. Hence we did not seek/obtain ethical approval and patient consent for the data analysis in this study.

\section{Exclusion Criteria}

The exclusion criteria for the patients in this study were as follows: patients with clear irreversible central nervous system damage, uncorrected abnormal cardiac anatomy, contraindications for anticoagulation, left ventricular rupture, dilated cardiomyopathy, and organ transplant transition.

\section{Research Methods}

The general characteristics of adult patients with cardiogenic shock treated with ECMO, the clinical indicators before and after the establishment of ECMO, complications, and hospital deaths were recorded. The status of patients at discharge was assessed, and the patients were divided into two groups based on the occurrence of in-hospital death. The possible prognostic risk factors were first obtained in a univariate analysis of the two groups, and the risk factors that affected the prognosis of ECMO were determined using a logistic regression (LR) analysis.

\section{Indications for ECMO}

The indications for ECMO were as follows: a cardiac index $(\mathrm{CI})<2 \mathrm{~L} \cdot \mathrm{m}-2 \cdot \mathrm{min}-1$; a pulmonary wedge pressure $>20$
$\mathrm{mmHg}$ with the administration of a large dose of inotropic drugs (dopamine $>15 \mu \mathrm{g} \cdot \mathrm{kg}^{-1} \cdot \mathrm{min}^{-1}$, epinephrine $>0.15 \mu \mathrm{g} \cdot \mathrm{kg}$ ${ }^{1} \cdot \mathrm{min}^{-1}$ or norepinephrine $\left.>0.15 \mu \mathrm{g} \cdot \mathrm{kg}^{-1} \cdot \mathrm{min}^{-1}\right)$, a mean arterial pressure $<60 \mathrm{mmHg}$, and increased blood lactate levels for metabolic acidosis indicated a $\mathrm{pH}$ level $<7.3$, a lactic acid level $>3.0$, and a urine volume $<0.5 \mathrm{ml} \cdot \mathrm{kg}-1 \cdot \mathrm{h}-1$ regardless of whether IABP support was provided; after conventional cardiopulmonary resuscitation (CPR) for sudden cardiac arrest, a stable and effective spontaneous circulation was not restored; severe arrhythmia (ventricular tachycardia, ventricular fibrillation) with no improvement after treatment with a variety of antiarrhythmic drugs, and hemodynamic instability; and heart deformity with satisfactory correction but the patient could not be weaned from cardiopulmonary bypass (CPB).

\section{Application of ECMO}

The ECMO perfusion system (Medtronic, Northridge, California, United States.) consisted of a bio-pump centrifugal pump, an oxygenator, a Stockert III water bath tank and a heparin-coated ECMO kit, a set of femoral artery and vein catheters, and an ACT detector.

The ECMO system was pre-filled with $1,000 \mathrm{~mL}$ saline for air exhaustion. The femoral artery and the femoral vein were cut open under direct vision, with systematic heparinization $(1 \mathrm{mg} / \mathrm{kg})$; the $15 \mathrm{Fr}-20 \mathrm{Fr}(10-15 \mathrm{~cm})$ and $19 \mathrm{Fr}-22 \mathrm{Fr}$ $(35-45 \mathrm{~cm})$ Medtronic heparin-coated catheters were respectively inserted through the femoral artery and vein for femoral vein-femoral artery (V-A) ECMO. In all patients, a distal perfusion catheter $(8 \mathrm{Fr}-10 \mathrm{Fr})$ was placed into the superficial femoral artery distal to the cannulation site in the common femoral artery. The distal perfusion catheter was connected to the femoral artery bypass [Slottosch 2013]. When an IABP was used, ECMO was placed at the side opposite to the IABP. The depth and location of the cannulation were confirmed using ultrasound or $\mathrm{X}$-ray.

In this study, ECMO was performed with a flow of 40-100 $\mathrm{mL} / \mathrm{kg} \cdot \mathrm{min}$. The mean arterial pressure was maintained at $>55 \mathrm{mmHg}$, and the blood temperature was maintained at $35-37^{\circ} \mathrm{C}$. The flow was comprehensively determined and adjusted according to the vital signs, echocardiography, chest $\mathrm{X}$-ray, and blood gas analysis. The administration of the vasoactive drug was gradually reduced but not completely withdrawn after the establishment of ECMO to prevent left ventricular expansion and to promote left ventricular

Table 2. General Characteristics of Patients with Cardiogenic Shock before Extracorporeal Membrane Oxygenation [X- $\pm S / M, Q / n,(\%)]$

\begin{tabular}{lccccc}
\hline & Total (94) & Survival Group (47) & Deceased Group (47) & $\mathrm{t} / \mathrm{Z} / \chi^{2}$ & $P$ \\
\hline Sex & & & & & \\
$\quad$ Male & $51(54.3)$ & $24(51.1)$ & $27(57.4)$ & 0.39 & .535 \\
$\quad$ Female & $43(45.7)$ & $23(48.9)$ & $20(42.6)$ & & \\
Age, $y^{* *}$ & $46.6 \pm 17.5$ & $41.7 \pm 13.1$ & $48.2 \pm 18.1$ & $2.00 \ddagger$ & $.049^{*}$ \\
Weight, kg** & $57.8 \pm 10.1$ & $57.0 \pm 9.6$ & $58.6 \pm 10.6$ & 0.78 & .439 \\
ECMO timing, $y^{* *}$ & $8.0(6.0)$ & $9.0(5.0)$ & $6.0(6.0)$ & 2.80 & $.005^{*}$
\end{tabular}


Table 2 CONTINUED. General Characteristics of Patients with Cardiogenic Shock before Extracorporeal Membrane Oxygenation $\left[\mathrm{X}^{-} \pm \mathrm{S} / \mathrm{M}, \mathrm{Q} / \mathrm{n},(\%)\right]$

\begin{tabular}{|c|c|c|c|c|c|}
\hline \multicolumn{6}{|l|}{ Disease history } \\
\hline Yes & $20(21.3)$ & $6(12.8)$ & $14(29.8)$ & \multirow[t]{2}{*}{4.07} & \multirow[t]{2}{*}{$.044 *$} \\
\hline No & $74(78.4)$ & $41(87.2)$ & $33(70.2)$ & & \\
\hline No & $79(84.0)$ & $42(89.4)$ & $37(78.7)$ & 1.98 & .159 \\
\hline \multicolumn{6}{|l|}{ Arrhythmias } \\
\hline Yes & $32(34.0)$ & $15(31.9)$ & $17(36.2)$ & \multirow[t]{2}{*}{0.19} & \multirow[t]{2}{*}{.663} \\
\hline No & $62(66.0)$ & $32(68.1)$ & $30(63.8)$ & & \\
\hline \multicolumn{6}{|l|}{ Kidney dysfunction } \\
\hline Yes & $2(2.1)$ & $0(0.0)$ & $4(8.5)$ & \multirow[t]{2}{*}{-} & \multirow[t]{2}{*}{.495} \\
\hline No & $92(97.9)$ & $47(100.0)$ & $45(95.7)$ & & \\
\hline \multicolumn{6}{|l|}{ Coronary heart disease } \\
\hline Yes & $23(24.5)$ & $8(17.0)$ & $15(31.9)$ & \multirow[t]{2}{*}{2.82} & \multirow[t]{2}{*}{.093} \\
\hline No & $71(75.5)$ & $39(83.0)$ & $32(68.1)$ & & \\
\hline \multicolumn{6}{|l|}{ Valvular disease } \\
\hline Yes & $45(47.9)$ & $21(44.7)$ & $24(51.1)$ & \multirow[t]{2}{*}{0.38} & \multirow[t]{2}{*}{.536} \\
\hline No & $49(52.1)$ & $26(55.3)$ & $23(48.9)$ & & \\
\hline \multicolumn{6}{|l|}{ CPR before ECMO } \\
\hline Yes & $23(24.5)$ & $7(14.9)$ & $16(34.0)$ & 4.66 & $.031 *$ \\
\hline No & & $71(75.5)$ & $40(85.1)$ & $31(66.0)$ & \\
\hline Lactate before ECMO, mmol/L†† & $6.7(5.3)$ & $5.3(3.3)$ & $8.2(6.5)$ & 3.88 & $<.001 *$ \\
\hline BNP before ECMO, pg/mL†† & $7,945.0(15,762.0)$ & $8,890.0(17,133.0)$ & $7,890.0(16,305.0)$ & 0.31 & .759 \\
\hline
\end{tabular}

CPR indicates conventional cardiopulmonary resuscitation; IABP, intraaortic balloon pump; BNP, B-type natriuretic peptide.

$* P<.05$.

$\dagger$ The theoretical frequency $<1$ for one lattice or the theoretical frequency $1 \leq T_{i j}<5$ for 2 or more lattices using Fisher exact test with no $\chi^{2}$ value. $\ddagger$ Heterogeneity of variance using the $t$ statistic.

**The numeric variable indicated a normal distribution, and the central tendency or dispersion trend was presented using $\mathrm{X}^{-} \pm \mathrm{S}$; the comparison between the two groups was performed using a t test.

$\dagger †$ The numeric variable was not normally distributed, and the central tendency or dispersion trend was presented using the median (M) and the interquartile range (Q). The comparison between the two groups was performed using the Wilcoxon rank-sum test. 
Table 3. Clinical Indicators and Outcomes of Patients with Cardiogenic Shock after Extracorporeal Membrane Oxygenation [M, Q, n (\%)]

\begin{tabular}{|c|c|c|c|c|c|}
\hline & Total (94) & Survival Group (47) & Deceased Group (47) & $\mathrm{Z} / \chi^{2}$ & $P$ \\
\hline Auxiliary time, $\mathrm{h} \dagger$ & $51.0(76.0)$ & $74.0(72.0)$ & $32.0(72.0)$ & 2.60 & .009 \\
\hline Yes & $16(17.0)$ & $9(19.1)$ & $7(14.9)$ & 0.30 & .583 \\
\hline No & $78(83.0)$ & $38(80.9)$ & $40(85.1)$ & & \\
\hline $\mathrm{RBC}$ transfusion, $\mathrm{mL} \dagger$ & $2,500.0(2,275.0)$ & $2,000.0(2,100.0)$ & $3,000.0(2,536.0)$ & 3.68 & $<.001 *$ \\
\hline Plasma transfusion, $\mathrm{mL} \dagger$ & $1,600.0(2,000.0)$ & $1,400.0(1,500.0)$ & $2,300.0(2,000.0)$ & 3.05 & $<.001$ * \\
\hline Platelet transfusion, $\mathrm{mL} \dagger$ & $200.0(200.0)$ & $200.0(200.0)$ & $400.0(400.0)$ & 2.33 & $.020 *$ \\
\hline Mechanical ventilation, $\mathrm{h} \dagger$ & $120.0(144.0)$ & $144.0(120.0)$ & $72.0(96.0)$ & 4.57 & $<.001$ * \\
\hline \multicolumn{6}{|l|}{ Complications } \\
\hline \multicolumn{6}{|l|}{ Cerebral hemorrhage } \\
\hline Yes & $3(3.2)$ & $0(0.0)$ & $3(6.4)$ & 3.10 & .078 \\
\hline No & $91(96.8)$ & $47(100.0)$ & $44(93.6)$ & & \\
\hline \multicolumn{6}{|l|}{ Gastrointestinal complications } \\
\hline Yes & $21(22.3)$ & $1(2.1)$ & $20(42.6)$ & 22.14 & $<.001$ * \\
\hline No & $73(77.7)$ & $46(100.0)$ & $27(57.4)$ & & \\
\hline \multicolumn{6}{|l|}{ Lower limb ischemia } \\
\hline Yes & $17(18.1)$ & $3(6.4)$ & $14(29.8)$ & 8.69 & $.003 *$ \\
\hline No & $77(81.9)$ & $44(93.6)$ & $33(70.2)$ & & \\
\hline No & $69(73.4)$ & $35(74.5)$ & $34(72.3)$ & & \\
\hline Lactate at weaning, $\mathrm{mmol} / \mathrm{L} \dagger$ & $1.48(5.66)$ & $1.10(0.58)$ & $6.75(7.70)$ & 7.01 & $<.001 *$ \\
\hline BNP at weaning, $\mathrm{pg} / \mathrm{mL} \dagger$ & 2,175.0 (17941.0) & $815.0(871.0)$ & $12,769.0(17,268.0)$ & 7.83 & $<.001 *$ \\
\hline
\end{tabular}

$* P<.05$. MOF indicates multiple organ failure.

†The numeric variable was not normally distributed, and the central tendency or dispersion trend was presented using the median ( $M$ ) and the interquartile range (Q). The comparison between the two groups was performed using the Wilcoxon rank-sum test.

ejection for thrombosis prevention. The mechanical ventilation mode during ECMO was synchronized intermittent mandatory ventilation plus pressure support (SIMV+PS), with a respiratory rate of $10-16$ beats/min, a tidal volume of $8-10 \mathrm{~mL} / \mathrm{kg}$, an inspired oxygen concentration of $40-60 \%$, and a peak airway pressure of $20 \mathrm{cmH}_{2} \mathrm{O}$ to avoid a high positive end-expiratory pressure (PEEP) $(\leq 8 \mathrm{mmHg})$. The ECMO gas flow rate was adjusted to maintain the body's normal arterial blood gas (arterial pressure of $80-150 \mathrm{mmHg}$ for $\mathrm{O}_{2}$, and 35-45 $\mathrm{mmHg}$ for $\mathrm{CO}_{2}$ ). Infusion of heparin was continued to maintain the activated clotting time (ACT) of approximately 160-200 s unless contraindications such as bleeding occurred. The infusion of red blood cells (RBCs), plasma, platelets, and clotting factor was performed based on the internal environment according to the laboratory results. A professional physician who specialized in extracorporeal perfusion checked the oxygenator and the thrombus daily to determine the oxygenation effect. The distal perfusion catheter was flushed with $10 \mathrm{~mL}$ heparin saline (concentration $1 \mathrm{mg} / 10 \mathrm{~mL}$ ) every two hours to prevent clogging. 
Table 4. Regression Model for the Included Variables and Their Assigned Values

\begin{tabular}{lc}
\hline & Assigned Value \\
\hline Prognosis & Survival $=0 ;$ death $=1$ \\
Age & Continuous variable \\
Duration of ECMO & Continuous variable \\
Lactate before ECMO & Continuous variable \\
Auxiliary time & Continuous variable \\
ECMO timing & Continuous variable \\
RBC transfusion & Continuous variable \\
Plasma transfusion & Continuous variable \\
Platelet transfusion & Continuous variable \\
Renal failure & No $=0 ;$ Yes $=1$ \\
Gastrointestinal complications & No $=0 ;$ Yes $=1$ \\
Lower limb ischemia & No $=0 ;$ Yes $=1$ \\
MOF & No $=0 ;$ Yes $=1$ \\
Lactate at weaning & Continuous variable \\
BNP at weaning & Continuous variable
\end{tabular}

\section{Withdrawal of ECMO}

The recovery of cardiac function can gradually reduce the flow of ECMO (1 L/min every 1-2 hours). Myocardial function was continuously assessed by echocardiography, with the measurement of cardiac metabolic parameters (cardiac output, pulmonary oxygen saturation, and lactate). When the circulatory and respiratory function of the patient was stable and could be sustained with moderate positive inotropic agents (epinephrine $<0.1 \mu \mathrm{g} \cdot \mathrm{kg}^{-1} \cdot \mathrm{min}^{-1}$ ) to reach an inspired oxygen concentration $<70 \%$ and an ECMO maximum flow of $1-2$ $\mathrm{L} / \mathrm{min}$, the removal of ECMO was considered. When withdrawing ECMO, the flow needed to be gradually reduced to $0.5 \mathrm{~L} / \mathrm{min}$ or lower, followed by a 0.5 -hour observation. When the circulation of the patients was stable, decannulation was conducted. Auxiliary IABP support was continued, and IABP parameters were appropriately adjusted. When the patient achieved stable circulation and recovery of heart function at a small dose of a vasoactive drug with no serious arrhythmia, the auxiliary IABP was stopped. The successful withdrawal of ECMO was defined as a patient survival of more than 48 hours after the removal of ECMO.

\section{Data Collection}

General patient data, clinical diagnoses, reasons for auxiliary ECMO, the clinical situation during ECMO, biochemical parameters during ECMO, and the prognoses of the patients who underwent ECMO were recorded. The general characteristics of the patients included age, weight, sex, basic medical history (diabetes, high blood pressure, liver and kidney dysfunction, arrhythmias, valvular disease, and pulmonary hypertension), type of surgery (coronary artery bypass, valve replacement, aortic replacement, or heart transplantation), duration of $\mathrm{CPB}$, cardiac occlusion time, the use of an IABP, and the use of heart compression before ECMO (including duration). The clinical situation during ECMO included the duration of auxiliary ECMO, the duration of mechanical ventilation, the timing of ECMO establishment (time from indication to the establishment of ECMO), CPR time, the need for continued IABP support during ECMO, the condition of the ECMO side branch (whether ischemia occurred), blood transfusion (the amount of RBC, plasma, and platelet transfusions), complications (whether renal failure, brain hemorrhage, infection, and gastrointestinal complications occurred). Hemodialysis treatment was needed for patients with postoperative renal failure. Postoperative renal failure was diagnosed in the presence of oliguria (less than $0.5 \mathrm{~mL} /$ $\mathrm{kg} / \mathrm{h}$ ) and a doubling of postoperative creatinine values (creatinine $\geq 442 \mu \mathrm{mol} / \mathrm{L}, 5 \mathrm{mg} / \mathrm{dL}$ ). The biochemical indicators during ECMO included the levels of lactate, B-type natriuretic peptide (BNP), cardiac enzymes (creatine kinase [CK] and creatine kinase isoenzyme $\mathrm{MB}[\mathrm{CK}-\mathrm{MB}])$, total bilirubin, and aspartate aminotransferase (AST) before ECMO and at weaning. The prognosis for survival referred to the successful discharge of patients from the hospital, and death was defined as a death that occurred in the hospital. The weaning time referred to the time until the successful withdrawal of ECMO and forced weaning due to a poor prognosis.

\section{Statistical Analysis}

According to the type of distribution, the measurement data are represented as the means \pm standard deviation $\left(\mathrm{X}^{-} \pm\right.$ S) or the statistical expressions of the median $(M)$ and the interquartile range (Q). The comparison between the groups was performed using the Student t test or the Wilcoxon ranksum test. The count data are represented by the statistical description of the percentage, and the comparison between the groups was conducted using the Pearson chi-square test or Fisher exact test. Statistically significant variables in the univariate analysis were applied to the LR in the multivariate analysis to determine the independent risk factors that affected prognosis. Differences with a $P$ value $<.05$ were considered statistically significant. SPSS 19.0.0 statistical software was used for the statistical analysis.

\section{RESULTS}

A total of 94 cardiogenic shock patients who were treated with ECMO were included in this study. The ages ranged from $18-86$ years, and the mean age was $46.6 \pm 17.5$ years. Overall, 59 patients were successfully weaned, which accounted for $62.7 \%$ of all patients. Additionally, 47 patients died in the hospital, whereas 47 patients survived in the hospital; therefore, the overall hospital survival rate was 50\%. In this study, 43 cardiogenic shock patients with low cardiac output after cardiac surgery were treated with ECMO. Of these patients, 32 were successfully weaned, 20 died in the hospital, and 23 survived in the hospital; therefore, the hospital survival rate was $53.4 \%$ in these patients. In addition, 18 cardiogenic shock patients with acute myocardial infarction were treated 
Table 5. Logistic Regression of Mortality in Patients with Cardiogenic Shock

\begin{tabular}{|c|c|c|c|c|c|c|c|}
\hline & Regression Coefficient & Standard Error & Wald $\chi^{2}$ & $P$ & OR & \multicolumn{2}{|c|}{$95 \% \mathrm{Cl}$} \\
\hline MOF & 7.946 & 2.681 & 8.785 & .003 & $2,823.09$ & 14.75 & $540,171.06$ \\
\hline Lactate at weaning, $\mathrm{mmol} / \mathrm{L}$ & 6.201 & 2.939 & 4.451 & .035 & 493.17 & 1.55 & $156,653.27$ \\
\hline
\end{tabular}

with ECMO. Of these patients, 7 were successfully weaned, 12 died in the hospital, and 6 survived in the hospital; therefore, the hospital survival rate was $33.3 \%$ in these patients. In addition, 21 cardiogenic shock patients with fulminant myocarditis were treated with ECMO. Of these patients, 16 were successfully weaned, 5 died in the hospital, and 16 survived in the hospital; therefore, the hospital survival rate was $76.2 \%$ in these patients (Table 1).

\section{Analysis of the Prognostic Factors of ECMO for Patients with Cardiogenic Shock}

A total of 94 patients with cardiogenic shock were included in this study. Overall, 47 deaths occurred in the hospital, and 47 patients survived in the hospital. General patient data before ECMO and the relevant clinical indicators and outcomes of ECMO were statistically described. All of the study subjects were divided into two groups according to whether death occurred in the hospital. The differences in the related indicators between the two groups were compared. The variables with significant differences were as follows: age; history of hypertension; ECMO duration; the use of chest compression before ECMO; the lactate level before ECMO; the time from the occurrence of indications to the establishment of ECMO (timing); the transfusion of blood products; the duration of mechanical ventilation; the occurrence of renal failure, concurrent gastrointestinal complications, lower limb ischemia, and multiple organ failure (MOF); the lactate level at weaning; and the level of BNP at weaning $(P<.05)$. The differences in the other variables, such as sex, were not statistically significant $(P>.05)$, as shown in Table 2 and Table 3.

The statistically significant variables in the univariate analysis were applied to the LR in the multivariate analysis (method: forward stepwise LR). The multivariate analysis revealed that the independent risk factors for prognosis were ECMO timing $(\mathrm{OR}=7.68$; 95\% CI 1.60-37.01), the occurrence of postoperative $\mathrm{MOF}(\mathrm{OR}=2823.09$; $95 \%$ CI 14.75 540,171.06), and the lactate level at weaning (OR = 493.17; $95 \%$ CI $1.55-156,653.27)$, as shown in Table 4 and Table 5.

\section{DISCUSSION}

ECMO can provide effective respiratory or circulatory support to critically ill patients with respiratory failure or cardiac failure, thereby allowing enough rest for the heart and the lung and gaining time for the restoration of cardiopulmonary function. This temporary substitution of cardiopulmonary function can reduce the cardiopulmonary load, ensure the perfusion of vital organs, and prolong the time to complete functional improvement and pathological restoration, thus helping patients to get through the critical stage. Advances in ECMO have made considerable progress in recent years, but the mortality rate remains high. Our center has achieved a degree of success with the application of ECMO; however, the mortality in this study was approximately $50 \%$, which is higher than the overall survival of $39 \%$ that was reported in a summary of the International Extracorporeal Life Support Organization [Paden 2013]. Many factors in the ECMO application process affect the prognosis of patients. Therefore, determining the risk factors that influence the prognosis of patients is particularly important because they will allow for the early identification and prevention of complications, which would improve the success rate of this treatment.

Numerous studies have proposed that renal failure, especially cases that require renal replacement therapy, is considered a risk factor of death in critically ill patients [Rastan 2010; Paden 2011]. Wu et al demonstrated that renal failure that requires hemodialysis during ECMO is an independent risk factor that affects ECMO weaning and survival prognosis [Wu 2008]. In this study, the multivariate regression analysis did not obtain a similar conclusion. One possible reason is that the renal failure was caused by poor cardiac function recovery, and the necrosis with ischemia and hypoxia in the kidney caused by severe renal circulatory failure before ECMO resulted in the overall failure of the patient.

The study by Kane et al suggested that E-CPR (ECMOaided cardiopulmonary resuscitation) can improve the prognosis of patients with sudden cardiac arrest who experience ineffective recovery with traditional methods [Kane 2010]. In this study, ECMO was used for these patients, but the success rate was only $30.4 \%$, which is lower than the success rate of $51 \%$ in the study by Kane et al [Kane 2010]. Their study concluded that CPR does not increase mortality with the application of ECMO, which is inconsistent with our findings. This difference may have been observed because the CPR treatment before ECMO in the present study was not effective and resulted in poor perfusion in systematic tissues and organs, thereby leading to hypoxic-ischemic necrosis in an irreversible state. The CPR treatment may have been ineffective because patients may have received chest compressions by non-professional persons outside of the hospital; therefore, acidosis and organ dysfunction may have occurred before ECMO was introduced.

The results of this study demonstrated that lower limb ischemia was a risk factor that affected the prognosis of 
patients. All of the patients in the current study underwent distal perfusion catheter placement at the side distal to the catheterization of the femoral artery, but lower limb ischemia still occurred because systemic perfusion in the patients was poor, which resulted in no improvement in cardiogenic shock. A large dose of vasoactive drugs may cause peripheral vasoconstriction, thereby leading to low perfusion, ischemia, and hypoxia. In addition, the diameter of the femoral artery catheterization was too large compared with the original femoral artery. The poor recovery of cardiac function in the patients resulted in low systemic perfusion, ischemia, and hypoxia in the side distal to the femoral artery catheterization, and the application of vasoconstrictor drugs exacerbated this effect. In addition, the released substances due to ischemia and hypoxia of the lower limb negatively impacted the heart.

Univariate analysis in this study also revealed that a high BNP level at weaning and the transfusion of blood products were risk factors for poor prognosis. BNP is a cardiac neurohormone that is released in ventricular cells after being stretched. The role of BNP levels in the diagnosis, prognosis, and treatment of heart failure has been recognized, and BNP has been internationally recognized as the best plasma marker of heart failure [Groenning 2004; Maisel 2002]. Recent studies have found that BNP levels were significantly increased in acute myocardial infarction and unstable angina attacks and can reflect the severity of heart disease [Groenning 2004; Maisel 2002]. Heart failure in patients with a poor prognosis is often unimproved, and infections and other complications may occur with extended support times, which together often leads to MOF and disseminated intravascular coagulation (DIC). The extremely harsh internal environment of patients requires a large amount of blood product transfusion for improvement. However, transfusion may increase the risk of immune suppression and microcirculatory disorders [Bittner 2007; Kumar 2010; Smith 2013].

This study revealed that the lactate level in the blood at weaning was an independent prognostic factor, and the lactate level before ECMO was related to the prognosis of the patients. One possible reason is that the lactate level in the blood can objectively reflect the extent of hypoxia damage in tissues and organs, whereas the severity of this damage is related to the prognosis of the patient [Bakhtiary 2008; Hsu 2010]. A high lactate level before ECMO and a high lactate level at weaning reflect systemic hypoperfusion of tissues and organs in patients, and further improvement in systemic perfusion is needed or patients with progressive failure will remain in an irreversible state. For critically ill patients, blood perfusion in organs should be improved as early as possible to improve the overall success rate of the treatment. However, the study by Bakhtiary et al did not obtain a similar conclusion [Bakhtiary 2008]. Our center recommends the close monitoring of lactate levels, which can serve as a variable in assessing cardiac circulation and response to treatment.

MOF and the time from the occurrence of indications to the establishment of ECMO were also indicated as independent risk factors for the prognosis of patients. MOF is a clinical syndrome with many causes, a complex pathogenesis, and a high mortality rate. MOF that occurred during
ECMO was related to the duration of hypoxia and ischemia in patients before ECMO and to the presence of infections and other complications during ECMO. MOF can cause further damage to the heart and is associated with reduced coronary blood flow, cardiac toxicity to endotoxin, the release of myocardial depression factor, and cardiac microcirculation disorders. The prolonged low cardiac output in the patients may have exacerbated ischemia and hypoxia in systemic tissues and organs, thereby leading to irreversible organ damage. The early application of ECMO may reduce hypoxia-induced myocardial damage, create conditions for reversible myocardial recovery, and enhance myocardial recovery. Therefore, ECMO should be applied and established as early and as rapidly as possible.

\section{Conclusion}

For patients with refractory cardiogenic shock, the early establishment of ECMO, improvement in perfusion, and the prevention of complications may improve the prognosis.

\section{ACKNOWLEDGEMENT}

\section{We acknowledge and thank our study participants.}

\section{REFERENCES}

Bakhtiary F, Keller H, Dogan S, et al. 2008. Venoarterial extracorporeal membrane oxygenation for treatment of cardiogenic shock: clinical experiences in 45 adult patients. J Thorac Cardiovasc Surg 135:382-8.

Bermudez CA, Rocha RV, Toyoda Y, et al. 2011. Extracorporeal membrane oxygenation for advanced refractory shock in acute and chronic cardiomyopathy. Ann Thorac Surg 92: 2125-31.

Bhat P, Hirsch JC, Gelehrter S, et al. 2013. Outcomes of infants weighing three kilograms or less requiring extracorporeal membrane oxygenation after cardiac surgery. Ann Thorac Surg 95:656-61.

Bittner HB, Binner C, Lehmann S, et al. 2007. Replacing cardiopulmonary bypass with extracorporeal membrane oxygenation in lung transplantation operations. Eur J Cardiothorac Surg 31:462-7; discussion 467.

Chaturvedi RR, Macrae D, Brown KL, et al. 2004. Cardiac ECMO for biventricular hearts after paediatric open heart surgery. Heart 90:545-51.

Cottini SR, Wenger U, Sailer S, et al. 2013. Extracorporeal membrane oxygenation: beneficial strategy for lung transplant recipients. J Extra Corpor Technol 45:16-20.

Davies A, Jones D, Bailey M, et al. 2009. Extracorporeal membrane oxygenation for 2009 influenza A(H1N1) acute respiratory distress syndrome. Australia, New Zealand Extracorporeal Membrane Oxygenation Influenza I. JAMA 302:1888-95.

Delius RE, Bove EL, Meliones JN, et al. 1992. Use of extracorporeal life support in patients with congenital heart disease. Crit Care Med 20:1216-22.

Fayssoil A, Nardi O, Orlikowski D, Combes A, Chastre J, Annane D. 2010. Percutaneous extracorporeal membrane oxygenation for cardiogenic shock due to acute fulminant myocarditis. Ann Thorac Surg 89:614-16.

Groenning BA, Raymond I, Hildebrandt PR, Nilsson JC, Baumann M, Pedersen F. 2004. Diagnostic and prognostic evaluation of left ventricular systolic heart failure by plasma $\mathrm{N}$-terminal pro-brain natriuretic 
peptide concentrations in a large sample of the general population. Heart 90:297-303.

Hill JD, O’Brien TG, Murray JJ, et al. 1972. Prolonged extracorporeal oxygenation for acute post-traumatic respiratory failure (shock-lung syndrome). Use of the Bramson membrane lung. N Engl J Med 286:629-34.

Hsu PS, Chen JL, Hong GJ, et al. 2010. Extracorporeal membrane oxygenation for refractory cardiogenic shock after cardiac surgery: predictors of early mortality and outcome from 51 adult patients. Eur J Cardiothorac Surg 37:328-33.

Kane DA, Thiagarajan RR, Wypij D, et al. 2010. Rapid-response extracorporeal membrane oxygenation to support cardiopulmonary resuscitation in children with cardiac disease. Circulation 122:S241-8.

Kim H, Lim SH, Hong J, et al. 2012. Efficacy of veno-arterial extracorporeal membrane oxygenation in acute myocardial infarction with cardiogenic shock. Resuscitation 83: 971-5.

Ko WJ, Chen YS, Chou NK, Wang SS, Chu SH. 1997. Extracorporeal membrane oxygenation in the perioperative period of heart transplantation. J Formos Med Assoc 96: 83-90.

Ko WJ, Lin CY, Chen RJ, Wang SS, Lin FY, Chen YS. 2002. Extracorporeal membrane oxygenation support for adult postcardiotomy cardiogenic shock. Ann Thorac Surg 73: 538-45.

Kumar TK, Zurakowski D, Dalton H, et al. 2010. Extracorporeal membrane oxygenation in postcardiotomy patients: factors influencing outcome. J Thorac Cardiovasc Surg 140: 330-6.e332.

Langley SM, Sheppard SV, Tsang VT, Monro JL, Lamb RK. 1998. When is extracorporeal life support worthwhile following repair of congenital heart disease in children? Eur J Cardiothorac Surg 13:520-5.

Maisel AS, Krishnaswamy P, Nowak RM, et al. 2002. Rapid measurement of B-type natriuretic peptide in the emergency diagnosis of heart failure. N Engl J Med 347:161-7.

Noah MA, Peek GJ, Finney SJ, et al. 2011. Referral to an extracorporeal membrane oxygenation center and mortality among patients with severe 2009 influenza A(H1N1). JAMA 306:1659-68.

Paden ML, Warshaw BL, Heard ML, Fortenberry JD. 2011. Recovery of renal function and survival after continuous renal replacement therapy during extracorporeal membrane oxygenation. Pediatr Crit Care Med 12:153-8.

Paden ML, Conrad SA, Rycus PT, Thiagarajan RR, Registry E. 2013. Extracorporeal Life Support Organization Registry Report 2012. ASAIO J 59:202-10.

Patroniti N, Zangrillo A, Pappalardo F, et al. 2011. The Italian ECMO network experience during the 2009 influenza A(H1N1) pandemic: preparation for severe respiratory emergency outbreaks. Intensive Care Med $37: 1447-57$.

Peek GJ, Mugford M, Tiruvoipati R, et al. 2009. Efficacy and economic assessment of conventional ventilatory support versus extracorporeal membrane oxygenation for severe adult respiratory failure (CESAR): a multicentre randomised controlled trial. Lancet 374: 1351-63.

Rastan AJ, Dege A, Mohr M, et al. 2010. Early and late outcomes of 517 consecutive adult patients treated with extracorporeal membrane oxygenation for refractory postcardiotomy cardiogenic shock. J Thorac Cardiovasc Surg 139:302-11.e301.

Slottosch I, Liakopoulos O, Kuhn E, et al. 2013. Outcomes after peripheral extracorporeal membrane oxygenation therapy for postcardiotomy cardiogenic shock: a single-center experience. J Surg Research $181: e 47-55$.

Smith A, Hardison D, Bridges B, Pietsch J. 2013. Red blood cell transfusion volume and mortality among patients receiving extracorporeal membrane oxygenation. Perfusion 28:54-60.

Tsao NW, Shih CM, Yeh JS, et al. 2012. Extracorporeal membrane oxygenation-assisted primary percutaneous coronary intervention may improve survival of patients with acute myocardial infarction complicated by profound cardiogenic shock. J Crit Care 27:530 e531-511.

Wu MY, Lin PJ, Tsai FC, Haung YK, Liu KS, Tsai FC. 2008. Impact of preexisting organ dysfunction on extracorporeal life support for nonpostcardiotomy cardiopulmonary failure. Resuscitation 79:54-60.

Yuan Y, Dong JT, Huang XS, et al. 2006. Successful extracorporeal membrane oxygenation support in a patient with fulminant myocarditis. Chin Med Sci J 21:194-6. 